\title{
Drug-Induced Hemolytic Anemia: A Fatal Complication Further Under-Recognized in Sickle Cell Disease
}

\author{
Monica Khurana ${ }^{1}$, Shekhar S. Raj ${ }^{2}$ \\ ${ }^{1}$ Department of Pediatric Hematology/Oncology, Indiana University Health, Indianapolis, IN, USA \\ ${ }^{2}$ Department of Pediatric Pulmonary and Critical Care, Indiana University Health, Indianapolis, IN, USA \\ Email: mkhurana@iu.edu
}

How to cite this paper: Khurana, M. and Raj, S.S. (2017) Drug-Induced Hemolytic Anemia: A Fatal Complication Further Under-Recognized in Sickle Cell Disease. Open Journal of Blood Diseases, 7, 79-85. https://doi.org/10.4236/ojbd.2017.73008

Received: July 18, 2017

Accepted: September 22, 2017

Published: September 25, 2017

Copyright (@) 2017 by authors and Scientific Research Publishing Inc. This work is licensed under the Creative Commons Attribution International License (CC BY 4.0).

http://creativecommons.org/licenses/by/4.0/

\section{(c) (i) Open Access}

\begin{abstract}
Drug-induced immune hemolytic anemia (DIIHA) is commonly attributed to cephalosporins. Ceftriaxone is the most frequently administered cephalosporin in patients with sickle cell disease. We present a pediatric patient with severe DIIHA (hemoglobin $<2 \mathrm{~g} / \mathrm{dl}$ ) who survived. Since DIIHA often goes undiagnosed until late in the course, vigilance of DIIHA minimizes unnecessary diagnostic tests and therapies. DIIHA likely remains under-recognized in all patient subpopulations due to its rarity and overlapping presentations with other conditions. Distinction between exacerbation of chronic hemolysis and new onset of acute hemolysis poses a unique challenge in patients with sickle cell disease. A thorough analysis is warranted to better identify factors within the pediatric sickle cell population that may increase the predisposition for DIIHA, particularly due to ceftriaxone.
\end{abstract}

\section{Keywords}

Sickle Cell, Hemolytic Anemia, Blood Bank, Pathology

\section{Introduction}

Drug-induced immune hemolytic anemia (DIIHA) is rare but potentially fatal. Unlike other immune cytopenias, the incidence of DIIHA is poorly estimated and less well characterized [1]. With an estimated annual incidence of 1 in 1 million [2], DIIHA comprises $>15 \%$ of acquired immune hemolytic episodes [3]. The two types of antibodies associated with DIIHA are drug-dependent and drug-independent. Serological differentiation between the two types of antibodies is necessary for clinical management. Drug-dependent antibodies yield a 
positive direct antiglobulin test with negative elution, thus making the direct antiglobulin test a cornerstone test in the diagnostic work-up of such acquired forms of DIIHA [4]. Although $>100$ drugs are implicated as causes of DIIHA today, ceftriaxone remains one of the most common culprits [5] [6]. This is particularly important as ceftriaxone is the most common empiric antibiotic administered in children with sickle cell disease (SCD) in the United States. This disproportionate incidence of high fatality rates from ceftriaxone-induced immune hemolytic anemia (CIIHA) is unique to children, as compared to adults [4], who have more comorbidities and poly-drug use [7]. Here, we present a child with SCD who experienced recurrent, severe intravascular hemolysis and actually survived. His course further highlights the rapidity of which ceftriaxone induces hemolysis in children ( $<1$ hour) and underscores how diagnostic delay in the setting of chronic hemolysis leads to numerous diagnostic tests. This case presentation supports the need to increase provider awareness, particularly among those caring for the sickle cell population, and inspires discussion about future interventions to decrease fatalities.

\section{Case Presentation}

Our patient is an 8 year-old African-American male with sickle cell anemia (hemoglobin SS) followed at an outside facility. He had a baseline hemoglobin $(\mathrm{Hb})$ of $7-8 \mathrm{~g} / \mathrm{dl}$, normal annual transcranial Dopplers, and updated vaccinations. Past medical history was most notable for remote acute chest syndrome and suspected parvovirus-induced aplastic anemia. Prior to this admission, the estimated number of lifetime red blood cell (RBC) transfusions was 5 - 6 times and lifetime doses of ceftriaxone, which were administered in the context of fever mostly in the emergency department (ED), was $<10$ times. He had not experienced any significant complications related to his underlying disease in the preceding 4 years.

Two weeks prior to transfer at our hospital, he complained of left elbow pain that was managed in the outpatient setting with ibuprofen and acetaminophen with codeine. Four days prior to transfer at our hospital, he developed intermittent fevers $\left(101^{\circ} \mathrm{F}\right)$ for which he received a single dose of ceftriaxone at $50 \mathrm{mg} / \mathrm{kg}$ and continued on clindamycin for cervical and submandibular lymphadenopathy. When fevers without a clear etiology became persistent $\left(103^{\circ} \mathrm{F}\right)$, family sought medical attention at the outside ED. There, he received a second dose of ceftriaxone and was admitted for further management.

On day of admission to this outside hospital, he was alert, oriented, and in no acute distress. Exam was also notable for mild hepatomegaly without jaundice. Labs revealed a white blood cell (WBC) count of 23,000 cells $/ \mathrm{mm}^{3}, \mathrm{Hb}$ near baseline at $7.4 \mathrm{~g} / \mathrm{dl}$, platelet count of $379,000 \mathrm{cells} / \mathrm{mm}^{3}$, and reticulocyte count of $34 \%$ with an absolute reticulocyte count of 250,000 cells $/ \mathrm{mm}^{3}$. Complete metabolic panel was overall unremarkable with creatinine of $0.2 \mathrm{mg} / \mathrm{dl}$, total bilirubin of $2.8 \mathrm{mg} / \mathrm{dL}$, alanine aminotransferase (ALT) of 119 units/l. 
On day 2 of admission, he complained of chest pain, became unresponsive, and eventually was transferred to the PICU at this same outside hospital. During this time, there was report of stiffened arms and tonic-clonic activity as well as tea-colored urine. Concurrent laboratory evaluation revealed $\mathrm{Hb}$ of $1.2 \mathrm{~g} / \mathrm{dl}$, which appropriately increased to $10.3 \mathrm{~g} / \mathrm{dl}$ after multiple units of packed RBCs. A platelet count of 34,000 cells $/ \mathrm{mm}^{3}$ in context of coagulopathy (PT/INR 24 seconds/2.2, aPTT 67 seconds, fibrinogen $<85 \mathrm{mg} / \mathrm{dl}$, D-Dimer $>10,000 \mu \mathrm{g} / \mathrm{L}$ ) raised concern for disseminated intravascular coagulation (DIC) and prompted cryoprecipitate transfusion. Additional notable labs included elevated liver transaminases (ALT 1240 units/l), lactate dehydrogenase (1111 units/l), and creatine phosphokinase (1400 units/l) as well as decreased haptoglobin $(<1$ $\mathrm{mg} / \mathrm{dl}$ ); blood bank evaluation revealed complement component (C3) positive $(+)$ and immunoglobulin $\mathrm{G}(\mathrm{IgG})$ negative $(-)$. Empiric coverage with ceftriaxone at the single daily dosing of $50 \mathrm{mg} / \mathrm{kg}$ was broadened to include vancomycin since blood cultures from the previous day were negative-to-date. Work-up confirmed myoglobulinuria on urinalysis (rather than hematuria), revealed no evidence of seizures on EEG (although anti-epileptic levetiracetam was already administered), showed no intracranial abnormality on head CT followed by brain MRI, demonstrated unremarkable plain films of the chest and abdomen followed by abdominal Doppler ultrasound given new findings of fever and abdominal complaints, and no evidence of perforation on abdominal/pelvis CT. Such a robust work-up represented the involvement of multiple pediatric subspecialty services, including critical care, hematology/oncology, infectious disease, surgery, neurology, and nephrology. Even though he was weaned off BiPAP a few hours after RBCs, he was transferred to our PICU for further management of sickle cell disease and multi-organ injury secondary to ischemic shock from hemolysis.

Shortly after arrival to our PICU (day 3 of hospitalization), he again complained of chest pain and became unresponsive and was eventually intubated for respiratory distress and acidosis $\left(\mathrm{pH} 7.22, \mathrm{PaCO}_{2} 20 \mathrm{mmHg}\right.$, bicarbonate 9 $\mathrm{mmol} / \mathrm{l})$. During this time, he again experienced tea-colored urine and urinalysis confirmed presence of myoglobulinuria. STAT serum/plasma evaluation revealed $\mathrm{Hb}$ of $2.6 \mathrm{~g} / \mathrm{dl}$, platelet count of 61,000 cells $/ \mathrm{mm}^{3}$, ALT of 1613 units/l, and total bilirubin of $5 \mathrm{mg} / \mathrm{dl}$. This prompted immediate intervention with pulse steroids and warmed RBCs throughout the day for immune hemolytic anemia. Hemoglobin increased to $12.9 \mathrm{~g} / \mathrm{dl}$, exceeding expectations based on the volumes transfused. However, nearly 24 hours later (day 4), Hb decreased to $6.4 \mathrm{~g} / \mathrm{dl}$; after $\mathrm{RBC}$ transfusions, $\mathrm{Hb}$ increased to $12.6 \mathrm{~g} / \mathrm{dl}$. This time, creatinine also increased and peaked to $0.48 \mathrm{mg} / \mathrm{dl}$.

The recurrent hemolysis (Figure 1) prompted further discussion among the hematology/oncology, blood bank, and apheresis (given the question of utility of plasmapheresis) services. Close review revealed that each severe hemolytic episode and decompensation occurred after drug administration, even at the 


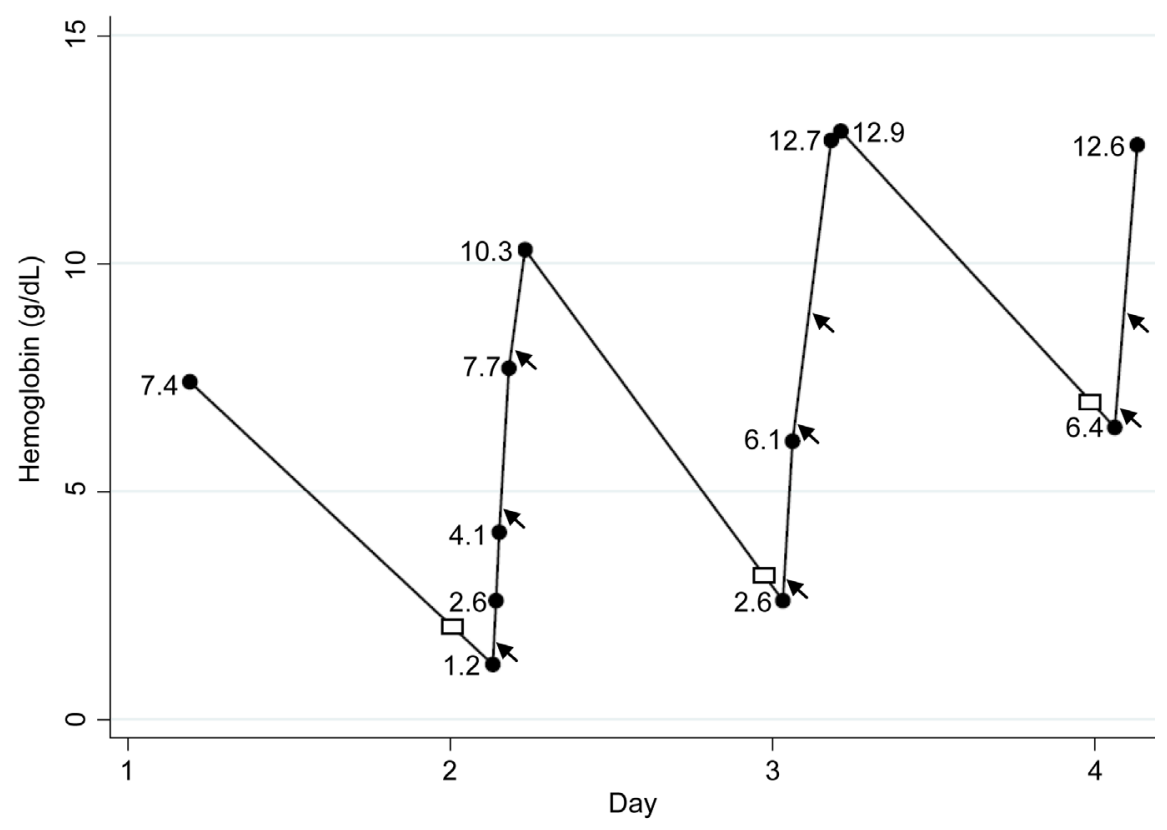

Figure 1. Episodic hemolytic anemia. Patient experienced three episodes of severe hemolytic anemia within four days. Each episode of hemolytic anemia occurred after ceftriaxone administration at $50 \mathrm{mg} / \mathrm{kg}$ (squares). Hemoglobin improved with each red blood transfusion (arrows) and stabilized $>10 \mathrm{~g} / \mathrm{dl}$ after ceftriaxone cessation.

outside hospital. With the possibility of DIIHA, ceftriaxone was discontinued. Within 48 hours of the last dose of ceftriaxone, drug-specific antibodies were sent to the Blood Center of Wisconsin Immunohematology Reference Laboratory. Interim extensive work-up in our blood bank was as follows: C3 (+), IgG $(-)$, cold agglutinin titer (-), Donath Landsteiner Ab (-). Although EBV IgM was positive, the remaining additional laboratory results obtained (given the broad differential) were unremarkable or non-contributory. These labs were as follows: viral hepatitis A, B, and C panels; pneumococcal antibodies to 23 serotypes; allergens; immunoglobulins; and electrophoresis ( $\mathrm{HbA} 61 \%$, S 36\%, A2 $3 \%$, consistent with transfusion). Imaging studies included repeat EEG, plain films, ultrasound, and CT as well as ECHO to follow-up cardiomegaly on CXR, which showed mild left ventricular hypertrophy but normal cardiac function. Again, such a robust work-up represented the involvement of multiple subspecialty services.

Within 24 hours of discontinuation of ceftriaxone, $\mathrm{Hb}$ stabilized $>10 \mathrm{~g} / \mathrm{dl}$ without transfusions and our patient was extubated with baseline mental status. Although creatinine normalized to baseline, hypertension persisted (>140/90 $\mathrm{mmHg}$ ). This was attributed to acute renal injury and likely exacerbated by pulse steroids; there was no associated hypertension-related retinopathy. Blood pressures were controlled with lisinopril and labetalol while inpatient. Within a month in the outpatient setting, he was weaned off both anti-hypertensive agents by the nephrology service. Prior to discharge, send-out labs finally confirmed ceftriaxone-dependent red cell alloantibodies (Table 1). At discharge, the infec tious 
Table 1. Drug-dependent RBC antibody.

\begin{tabular}{cc}
\hline Test & Result \\
ABO Rh & $\mathrm{A}+$ \\
Polyspecific Ab & $1+$ \\
Anti-IgG & $(-)$ \\
Anti-C3 & $1+$ \\
Anti-C3d & $1+$ \\
Saline control & $(-)$ \\
Eluate from patient's RBCs & $(-)$ \\
Drug-dependent Ab study & Ceftriaxone-dependent RBC Ab \\
\hline
\end{tabular}

The direct antiglobulin test was positive due to complement binding to the patient's red cells. Further serological testing was performed at the Blood Center of Wisconsin Immunohematology Reference Laboratory. Results revealed that the antibodies in the patient's serum reacted in vitro with the patient's RBCs only i $\mathrm{nt}$ he presence of ceftriaxone, leading to a diagnosis of DIIHA. RBC, red blood cell; DIIHA, drug induced immune hemolytic anemia; $\mathrm{Ab}$, antibody.

disease service recommended empiric coverage with levofloxacin for future fevers and reiterated avoidance of ceftriaxone.

\section{Discussion}

Vigilance of DIIHA in children remains challenging given its under-recognition and paucity of published data. The lack of a well-established incidence cannot be merely attributed to its rarity, as the incidence to other immune cytopenias has been documented [1]. There are varying proposals of mechanisms of actions accounting for DIIHA over the decades-the most recent is the unifying hypothesis-that underscores how the intricacies of DIIHA have yet to be fully elucidated. Further complicating our understanding is the rapidly changing drug landscape that leads to new culprits triggering DIIHA [6]. The first documented cases were in the 1950s and attributed to mephenytoin and stibophen [8] [9] [10]. During the 1970s, the most common pharmacological trigger was methyldopa, accounting for $>60 \%$ of DIIHA cases, followed by penicillin [1] [11]. Since the 1990s, most DIIHA cases were due to the second- and third-generation cephalosporins, shortly after its commercial introduction into medicine [11]. Yet, perhaps the most impressive hindrance to documenting DIIHA may be from the intense and unique laboratory evaluations required for diagnosis. Definitive diagnosis requires demonstration of serum ceftriaxone antibodies in the presence of ceftriaxone. Since ceftriaxone does not bind as strongly to RBC membranes, it is difficult to create drug-coated RBCs for in vitro testing [6]. Access to such high sensitivity and specificity serological investigations is limited to several reference laboratories in the country that have adequate resources and experienced staff [7]. Additionally, the long turnaround time may deter pursuit of testing for drug antibiotics, as changes in acute management would be necessary prior to available results. 
DIIHA, particularly CIIHA, in SCD is further under-recognized, albeit unintentionally, thereby placing thousands of children at risk for fatal hemolysis. If there is a paucity of published data of DIIHA in the general population, then it is not surprising that there is even less in the sickle cell population. Despite improved understanding of ceftriaxone-induced antibodies, data regarding CIIHA in SCD remain scant. The most informative available literature regarding this topic was in 2008 [12]; excluding this study, only case reports have been published. Evaluation of blood samples from 19 pediatric and adult patients with SCD revealed the prevalence of anti-ceftriaxone antibody as 5.3\% [12]. Statistics for the prevalence of SCD in the U.S. has yet to be updated, but was last estimated to be 100,000 individuals [13]. Incidence of SCD in the U.S. is $\sim 1$ in 2500, making it the most common condition identified on newborn screening [14]. Based on this data, $>5000$ individuals with SCD would be expected to be at risk for CIIHA in the United States! Yet, there is a marked lack of early recognition of the presenting signs and symptoms.

Specific contributors to the further under-recognition of CIIHA in SCD are: 1) the false reassurance among providers that a particular patient with SCD has tolerated multiple doses of ceftriaxone, and 2) misdiagnosis of hemolysis as a complication associated with SCD or an intervention. False reassurance among providers can be appreciated in the case report of a two-year-old male with $\mathrm{Hb}$ SS who developed severe hemolysis $(\mathrm{Hb}<1 \mathrm{~g} / \mathrm{dl})<30$ minutes after his $15^{\text {th }}$ lifetime dose of ceftriaxone. Post-mortem serologies confirmed antibodies to ceftriaxone and a retrospective chart review revealed that he experienced 5 prior transient episodes of hemoglobinuria immediately after ceftriaxone [15].

Perhaps the more important contributor is a misdiagnosis that leads to unnecessary diagnostic procedures and therapeutic interventions at hospitals, as demonstrated in our case report. The presentation of hematuria due to CIIHA parallels the presentation of hematuria due to sickle cell-related nephropathy microinfarcts in renal papillae. The dramatic drop in $\mathrm{Hb}$ due to CIIHA may be labelled as an exacerbation of chronic hemolysis (aka acute sickling crisis) or transfusion reaction, either hemolytic or delayed. Overlapping clinical presentations also include warm autoimmune hemolytic anemia, as patients with SCD have the same risk of this as the general population, and clinical sepsis due to hyposplenic function $+/-$ DIC.

Given the high prevalence of SCD, the frequent use of ceftriaxone per pediatric empiric infectious standard of care guidelines, and the delayed diagnosis that increases adverse outcomes, a thorough analysis is warranted to better identify factors within the pediatric sickle cell population that may increase the predisposition for CIIHA. Anticipated benefits of a thorough analysis would encourage earlier recognition of DIIHA in children with SCD, thereby decreasing pediatric patient fatality via increased awareness and screening. At the very least, it should minimize invasive diagnostics and unnecessary costly therapeutic interventions. In response to this case, we have initiated a state-wide review to better 
identify risk factors within the pediatric sickle cell population that increases the predisposition for DIIHA. We encourage other institutions to explore possibilities of how to mitigate this fatal complication, particularly in patients with SCD.

\section{References}

[1] Garratty, G. (2010) Drug-Induced Immune Hemolytic Anemia. Clinical Advances in Hematology \& Oncology, 8, 98-101.

[2] Garratty, G. (2010) Immune Hemolytic Anemia Associated with Drug Therapy. Blood Reviews, 24, 143-150.

[3] Thomé, S.D. and Petz, L.D. (2002) Manual of Clinical Hematology. In: Mazza, J.J., Ed., Hemolytic Anemia: Hereditary and Acquired, Lippincott Williams and Wilkins, Pennsylvania, 90-117.

[4] Pierce, A. and Nester, T. (2011) Pathology Consultation on Drug-Induced Hemolytic Anemia. American Journal of Clinical Pathology, 136, 7-12. https://doi.org/10.1309/AJCPBVLJZH6W6RQM

[5] Guleria, V.S., Sharma, N., Amitabh, S. and Nair, V. (2013) Ceftriaxone-Induced Hemolysis. Indian Journal of Pharmacology, 45, 530-531. https://doi.org/10.4103/0253-7613.117758

[6] Arndt, P.A. and Garratty, G. (2005) The Changing Spectrum of Drug-Induced Immune Hemolytic anemia. Seminars in Hematology, 42, 137-144.

https://doi.org/10.1053/j.seminhematol.2005.04.004

[7] Neuman, G., Boodhan, S., Wurman, I., Koren, G., Kirby-Allen, M. and Ito, S. (2014) Ceftriaxone-Induced Immune Hemolytic Anemia. Annals of Pharmacotherapy, 48, 1594-1604. https://doi.org/10.1177/1060028014548310

[8] Snapper, I., Marks, D., Schwartz, L. and Hollander, L. (1953) Hemolytic Anemia Secondary to Mesantoin. Annals of Internal Medicine, 39, 619-623. https://doi.org/10.7326/0003-4819-39-3-619

[9] Harris, J.W. (1954) Studies on Mechanism of Drug-Induced Hemolytic Anemia. Journal of Laboratory and Clinical Medicine, 44, 809-810.

[10] Harris, J.W. (1956) Studies on Mechanism of Drug-Induced Hemolytic Anemia. Journal of Laboratory and Clinical Medicine, 47, 760-775.

[11] Garratty, G. (2009) Drug-Induced Immune Hemolytic Anemia. ASH Education Book, 2009, 73-79. https://doi.org/10.1182/asheducation-2009.1.73

[12] Quillen, K., Lane, C., Hu, E., Pelton, S. and Bateman, S. (2008) Prevalence of Ceftriaxone-Induced Red Blood Cell Antibodies in Pediatric Patients with Sickle Cell Disease and Human Immunodeficiency Virus Infection. Pediatric Infectious Disease, 27, 357-358. https://doi.org/10.1097/INF.0b013e3181629a55

[13] Centers for Disease Control and Prevention (2011) Sickle Cell Disease. Data \& Statistics. http://www.cdc.gov/ncbddd/sicklecell/data.html

[14] Sickle Cell Disease. American Academy of Pediatrics. https://www.aap.org/en-us/about-the-aap/committees-councils-sections/section-he matology-oncology/documents/scd_factsheet.pdf

[15] Bernini, J.C., Mustafa, M.M., Sutor, L.J. and Buchanan, G.R. (1995) Fatal Hemolysis Induced by Ceftriaxone in a Child with Sickle Cell Anemia. Journal of Pediatrics, 126, 813-815. 
Submit or recommend next manuscript to SCIRP and we will provide best service for you:

Accepting pre-submission inquiries through Email, Facebook, LinkedIn, Twitter, etc. A wide selection of journals (inclusive of 9 subjects, more than 200 journals)

Providing 24-hour high-quality service

User-friendly online submission system

Fair and swift peer-review system

Efficient typesetting and proofreading procedure

Display of the result of downloads and visits, as well as the number of cited articles Maximum dissemination of your research work

Submit your manuscript at: http://papersubmission.scirp.org/

Or contact ojbd@scirp.org 